\title{
A rare case of dicephalic parapagus conjoined twins
}

\section{Edouard N'Guessan ${ }^{1 *}$, Roseline Kouame N'Guessan², Franck Gbeli' ${ }^{1}$, Privat Guie ${ }^{1}$}

\author{
${ }^{1}$ Department of Obstetrics and Gynaecology, Treichville University Hospital, Abidjan, Côte d'Ivoire \\ ${ }^{2}$ Department of Pediatrics, College of Medicine, Felix Houphouet-Boigny University, Abidjan, Côte d'Ivoire
}

Received: 16 October 2019

Revised: 22 November 2019

Accepted: 02 December 2019

\section{*Correspondence:}

Dr. Edouard N'Guessan,

E-mail: k.ed.nguessan@gmail.com

Copyright: $@$ the author(s), publisher and licensee Medip Academy. This is an open-access article distributed under the terms of the Creative Commons Attribution Non-Commercial License, which permits unrestricted non-commercial use, distribution, and reproduction in any medium, provided the original work is properly cited.

\begin{abstract}
Dicephalic parapagus are one of the rare forms of conjoined twins. Their prognosis is usually very poor. Early prenatal diagnosis of these serious congenital abnormalities remains a real challenge for health systems in the lowincome countries. The late antenatal diagnosis of a case of this abnormality was presented. The diagnosis was made at the $33^{\text {rd }}$ week on the only ultrasound performed during the pregnancy. The pregnancy was interrupted with the agreement of the couple and delivery was performed by caesarean section.
\end{abstract}

Keywords: Conjoined twins, Dicephalus, Parapagus, Ultrasonography

\section{INTRODUCTION}

Conjoined twins are rare malformations of monozygotic monoamniotic twins affecting between 1 in 50,000 and 1 in 100,000 births. ${ }^{1}$ They are expressed by a fusion zone between fetuses that allow the definition of the type of conjoined twins. Dicephalic parapagus are an extremely rare variety in which the laterally united twins have two heads with a single trunk. ${ }^{2}$ The prognosis of this form is very poor. ${ }^{3}$ Early prenatal diagnosis is possible and remains determinant for optimal management. Unfortunately, this early diagnosis remains a real challenge in the countries with limited resources.

This is a report of a rare case of Dicephalic parapagus that was diagnosed late on trans-abdominal ultrasound.

\section{CASE REPORT}

A 24-year-old female patient was referred to this department for the inconclusive result of her first obstetrical ultrasound scan performed at the $32^{\text {nd }}$ week of pregnancy. Her pregnancy was poorly monitored without biological or ultrasound assessment. The patient had a family history of twins, but there was no family history of congenital abnormality or personal toxic substance intake during this pregnancy.

Two-dimensional trans-abdominal ultrasound showed a twin pregnancy at week 33 . The breech fetuses had two heads next to each other with only one trunk, one heart activity center and one placenta. The amount of amniotic fluid was normal. On these ultrasound arguments, the diagnosis of dicephalic parapagus conjoined twins was evoked.

The couple informed of these results and the poor prognosis of this abnormality had opted for an interruption of the pregnancy. The delivery was performed by caesarean section. The conjoined twins had a combined weight of $2700 \mathrm{~g}$ with an Apgar score of 3 in the first minute and 0 in the $5^{\text {th }}$ minute. 


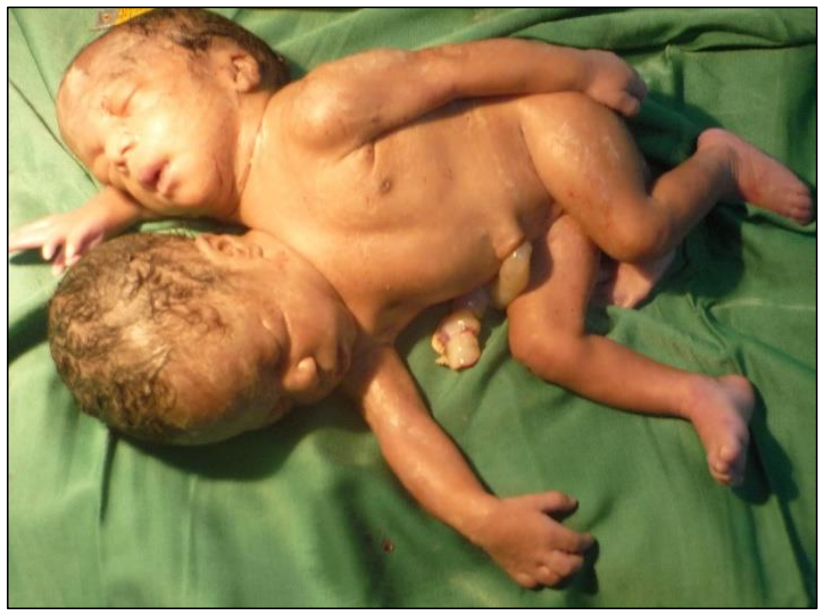

Figure 1: Parapagus dicephalic conjoined twins: anterior view showing three upper limbs and three lower limbs.

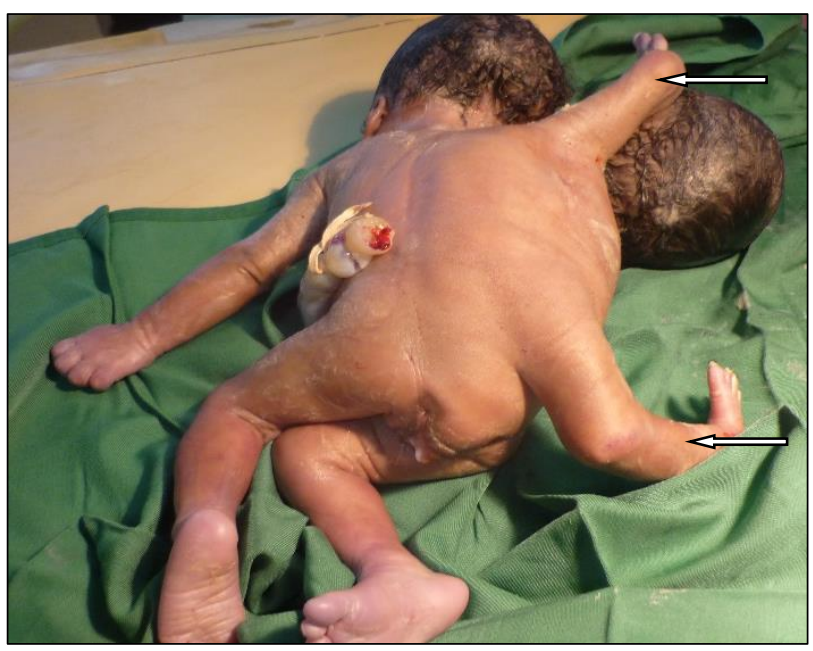

Figure 2: Parapagus dicephalic conjoined twins: posterior view showing two rudimentary hind limbs (arrow).

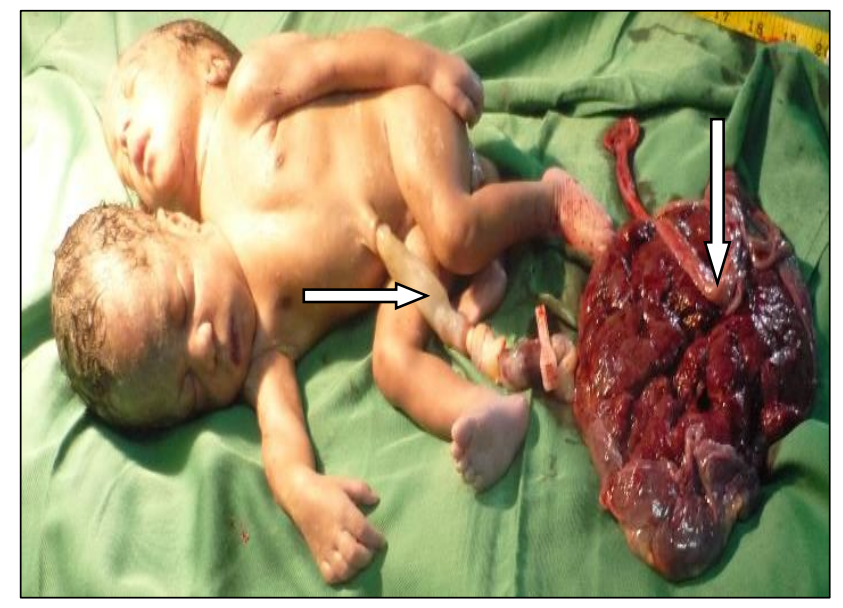

Figure 3: Parapagus dicephalic conjoined twins: anterior view showing single placenta (white arrow) and single umbilical cord (black arrow).
The neonatal examination, confirmed the diagnosis of dicephalic parapagus conjoined twins. There were two heads and two necks, a thorax and a single abdomen (Figure 1). Author noted 3 upper limbs and 3 lower limbs with four normal forelimbs and two rudimentary hind limbs (Figure 2). In addition, there was only one female gender, an imperforate anus. Finally, a single placenta was noted weighing $430 \mathrm{~g}$ and a single $34 \mathrm{~cm}$ central umbilical insertion cord with three vessels (Figure 3). The family did not authorize the autopsy. The postoperative period was uneventful for the patient who was discharged on the fourth day after caesarean section.

\section{DISCUSSION}

Conjoined twins are rare congenital abnormalities that involve between 1 in 50,000 to 1 in 100,000 births and about 1 per 200 monozygotic pregnancies. ${ }^{1}$ Their incidence in Sub-Saharan Africa is unknown, only a few case reports were found. ${ }^{4}$

Embryologically, two opposing theories were proposed to explain the clinical polymorphism of these malformations. This is the late incomplete separation of the embryonic disk (fission theory) and the secondary fusion between two previously separated embryonic disks (fusion theory). ${ }^{2}$

Conjoined twins are classified according to the area of fusion between both fetuses. This union is predominantly ventral and dorsal. The terms "parapagus" refer to a sideby-side lateral fusion of twins. ${ }^{2}$ It is an extremely rare variety, observed in less than $0.5 \%$ of the reported cases of conjoined twins. ${ }^{3}$ Parapagus conjoined twins share the same trunk but have either two distinct heads (dicephalic parapagus) or a single head with 2 different faces (diprosopus parapagus). ${ }^{2,3}$ They can have 2 to 4 arms and 2 or 3 legs. ${ }^{3}$ In the observation, the twins had only one thorax, one abdomen, two heads, three upper limbs and three lower limbs. It was therefore, parapagus dicephalic tribrachius tripus, which is an outstanding variety of conjoined twins. ${ }^{3}$

The exact pathogenic mechanism of conjoined twins remains obscure. No etiology or specific associated factor was observed. If all conjoined twins are considered, there is a clear female predominance; however, parapagus seem more common in males. ${ }^{1}$

Early prenatal diagnosis of these abnormalities is possible from the $10^{\text {th }}$ week of pregnancy on two-dimensional ultrasound. ${ }^{5}$ As in observation, the diagnosis of conjoined twins in under-medicalized countries is often late because of the difficulties of access to prenatal care and ultrasound. ${ }^{4,6}$ Ultrasound also allows lesional assessment. MRI provides a more accurate anatomical assessment of lesions, but its use in the practice is exceptional because of its high cost. ${ }^{7}$ This accurate prenatal diagnosis is essential for assessing prognosis and guiding therapeutic management. It allows practitioners to provide parents 
with useful information that will help them decide whether to continue the pregnancy. ${ }^{1}$

The prognosis of conjoined twins is correlated with the degree of fusion of the organs and the severity of the associated malformations. This prognosis is poor when the conjoined twins share the same heart as it is constantly the case of dicephalic parapagus because this unique heart has serious morphological abnormalities incompatible with life or surgical separation., ${ }^{3,8}$ Thus, the majority of dicephalic parapagus reported in the literature died in utero or immediately after birth, as in this case. ${ }^{1,3}$ And the few surviving cases remained inaccessible to the separation surgery of the twins after birth. ${ }^{3}$

\section{CONCLUSION}

Conjoined twins are rare, but serious malformations who's exact etiology is uncertain. They are in most cases non-viable and rarely meet the technical and ethical requirements of surgical separation after birth. An early and accurate prenatal diagnosis is therefore essential to optimize their management. This early diagnosis remains a challenge in the countries with limited resources. Improving access to prenatal care and training of fetal medicine specialists should help meet this challenge.

Funding: No funding sources

Conflict of interest: None declared

Ethical approval: Not required

\section{REFERENCES}

1. Mutchinick OM, Luna-Muñoz L, Amar E, Bakker MK, Clementi M, Cocchi G, et al. Conjoined twins: a worldwide collaborative epidemiological study of the International Clearinghouse for birth defects surveillance and research. Am J Med Genet C (Semin Med Genet). 2011;157:274-87.

2. Spencer R. Anatomic description of conjoined twins: a plea for standardized terminology. J Pediatr Surg. 1996;31:941-7.

3. Başaran S, Güzel R, Keskin E, Sarpel T. Parapagus (dicephalus, tetrabrachius, dipus) conjoined twins and their rehabilitation. Turk J Pediatr. 2013;55(1):99-103.

4. Blé RK, Séni K, Adjoussou S, Quenum G, Akaffou E, Koné M. Craniopagus conjoined twins: difficulties of management in Africa. Gynecol Obstet Fertil. 2008;36(1):56-9.

5. Cuillier F, Dillon KC, Grochal F, Scemama JM, Gervais T, Cerekja A, et al. Conjoined twins: what ultrasound may add to management. J Prenat Med 2012;6:4-6.

6. De Silva RS, Amaradivakara PW. Antenatal Diagnosis and management of conjoined twins: a case report. SLJOG. 2015;37(2):24-6.

7. Mathew RP, Francis S, Basti RS, Suresh HB, Rajarathnam A, Cunha PD, et al. Conjoined twinsrole of imaging and recent advances. J Ultrason. 2017;17(71):259-66.

8. Tansel T, Yazicioğlu F. Cardiac and other malformations in parapagus twins. Arch Gynecol Obstet. 2004;269(3):211-3.

Cite this article as: N'Guessan E, N'Guessan RK, Gbeli F, Guie P. A rare case of dicephalic parapagus conjoined twins. Int J Reprod Contracept Obstet Gynecol 2020;9:415-7. 